\title{
Training Model for 21st Century Graduate Education Through Engagement to Action
}

\author{
Meredith Welch-Devine, University of Georgia \\ Dr. Ramana Pidaparti, University of Georgia
}

Ramana Pidaparti, is currently a Professor of Mechanical Engineering at VCU. Dr. Pidaparti received his Ph.D. degree in Aeronautics \& Astronautics from Purdue University, West Lafayette in 1989. In 2004, he joined the Virginia Commonwealth University as a Professor of Mechanical Engineering. He has taught previously at Purdue University campus in Indianapolis (IUPUI). He has taught several courses in design, mechanics of materials, optimization, and directed many interdisciplinary projects related to design. Dr. Pidaparti's research interests are in the broad areas of multi-disciplinary design, computational mechanics, nanotechnology, and related topics. Dr. Pidaparti has published over 250 technical papers in refereed journals and conference proceedings. Dr. Pidaparti received a Research Initiation Award from the National Science Foundation and the Young Investigator Award from the Whitaker Foundation. He is a member of Tau Beta Pi, Sigma Gamma Tau, and Who's Who societies. He is a member of professional societies including AIAA (Associate Fellow), AAAS (Fellow), ASME (Fellow), RAeS (Fellow), and ASEE (member). Dr. Pidaparti will move to University of Georgia in January 2014 as a professor of mechanical engineering.

\section{Dr. K. Paige Carmichael, University of Georgia}

Dr. K. Paige Carmichael is a Josiah Meigs Distinguished Professor of Pathology, a Board Certified Pathologist and an award winning Instructor at the University of Georgia College of Veterinary Medicine. She is the sole clinician on the CVM Ocular Biopsy Service. Her research interests include animal models of human neurological disease and Ocular Pathology. She received her B.S. in 1983 and DVM. In 1987 from the Tuskegee University School of Veterinary Medicine. She received a PhD from University of Georgia in 1993 and became Board Certified in 1995. She joined the faculty at UGA in the Department of Pathology. In 2006, she served the College as Associate Dean for Academic Affairs. After eight years, she returned to faculty and developed a passion for the best practices of facilitating learning and the mentoring process.

\section{Dr. Janet E. Rechtman, University of Georgia}

Dr Janet Rechtman is a Senior Fellow at J.W. Fanning Institute for Leadership Development at University of Georgia. With more than 30 years of experience as a volunteer leader and consultant to nonprofit organizations, Janet provides technical assistance to nonprofit organizations in areas of strategic planning, evaluation, marketing and communications, as well as individual coaching and leadership development. Her doctoral dissertation, which documented the lived experience of nonprofit executive directors, provides a foundation for her focus on leadership as a way of being for staff and volunteer leaders in the sector.

\section{Dr. Brandy B. Walker, University of Georgia}

Dr. Brandy Walker is public service faculty at the J.W. Fanning Institute for Leadership Development at the University of Georgia. She holds a Ph.D. in Learning, Design, and Technology and is interested in applied research on perspective changes in community contexts, experiential learning in higher education, and community-engagement.

Dr. Julie A. Coffield, University of Georgia 
2018 AEEE Annual Conference \& Exposition, June 24 - 27, 2018, Salt Lake City, Utah

ASEE Graduate Studies Division

\title{
Training Model for $21^{\text {st }}$ Century Graduate Education through Engagement to Action
}

\author{
Julie Coffield, Meredith Welch-Devine, Brandy Walker, Paige Carmichael, Paul Brooks, \\ Janet Rechtman, Andy Kavoori, Jasmine Choi, Sejin Kim, Katie Walters, Janette Hill, \\ Ike Choi, and Ramana Pidaparti* \\ University of Georgia, Athens, GA 30602 \\ *Corresponding author, E-mail: rmparti@uga.edu
}

\begin{abstract}
Twenty-first century scientists and engineers must possess skills that enable them to reach beyond the laboratory, across disciplines, and into communities to identify issues and develop solutions that increase both resilience and sustainability. The need to make $21^{\text {st }}$ century graduate education training requires educators to develop innovative approaches that provide critical professional skills that transcend discipline and prepare students for a broad range of career choices. In this study, a novel approach was developed for STEM graduate education that aligns professional skill training with experiential learning pedagogy adopted from training models in the health professions. The training model designed for a cohort of newly admitted $\mathrm{PhD}$ students consists of two components, an immersive summer program (Leadership Academy), followed by a fall Challenge Course. The goals of the training model is to impart the following competency themes: interdisciplinary mindsets; community engagement; understanding self as a leader; professional identity; and STEM scholar leader. First cohort of graduate students was recruited in summer 2016. After students completed the training model, the assessment and reflective student posts indicated that students indeed do develop most of the competencies. Based on our preliminary experience, specific scenarios for community collaboration as well as challenge projects should be explored to further promote competencies in graduate education.
\end{abstract}

\section{Keywords}

Graduate Education, Training Models, Competencies, Leadership, Community, Engagement 


\section{Introduction}

Rapid advances in technology and scientific knowledge coupled with dynamic changes in global societies call for a STEM workforce that is not only technically advanced in their disciplines, but also readily adaptable and responsive to evolving and emerging opportunities. Twenty-first century scientists and engineers must possess skills that enable them to reach beyond the laboratory, across disciplines, and into communities to identify issues and develop solutions that increase both resilience and sustainability. To prepare this new kind of leader, graduate training must embrace innovative approaches that inculcate critical professional skills that transcend disciplines and prepare STEM students for a diverse range of career choices [1]-[5]. Public institutions of higher education, particularly those with land/sea grant missions such as the University of Georgia, are uniquely positioned to offer graduate students a broad array of training opportunities that bridge multiple disciplines and allow them to engage with communities on issues of pressing importance. With this in mind, the University of Georgia Graduate School partnered with several academic and public service units to develop a novel interdisciplinary model for STEM doctoral education (see Figure 1). This novel strategy aligns professional skills training with experiential learning pedagogy adapted from training models in the health professions [6][10]. A major focus of this model is the alignment of graduate STEM education with community engagement [11] and interdisciplinary teamwork [12]-[13].

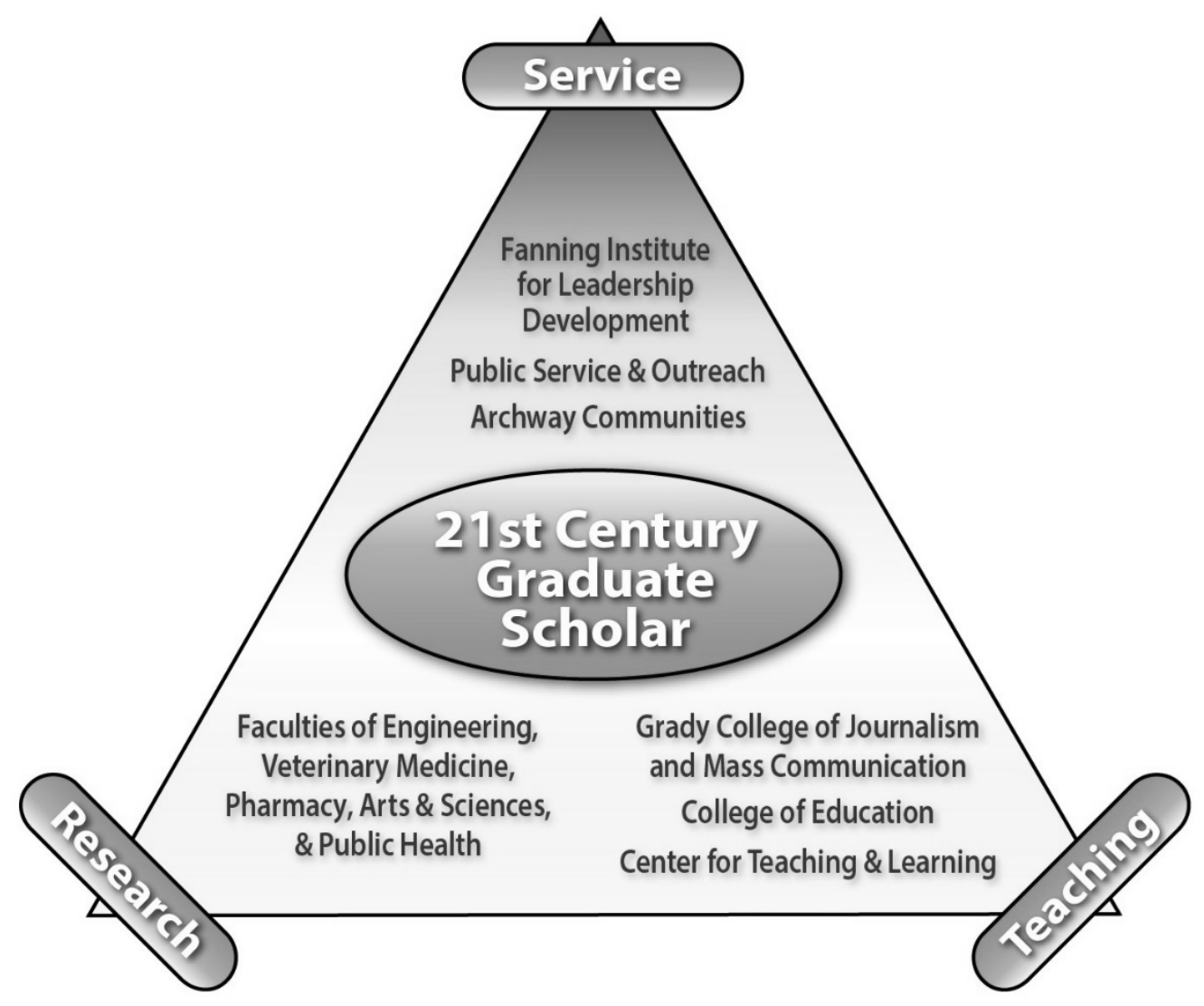

FIGURE 1. 21 ${ }^{\text {st }}$ Century Scholar 
The training model described in this paper is designed for newly admitted doctoral students from a broad array of STEM fields. The approach consists of two major components, (1) an immersive summer program, followed by (2) a fall challenge course. This pilot training program, known as Graduate Scholars Leadership, Engagement and Development (GS LEAD), is funded for three years through an Innovations in Graduate Education (IGE) grant from the National Science Foundation awarded to the University of Georgia. The goals of GS LEAD are to combine transferable skills training with reflective experiential learning opportunities, so that students develop both foundational and applied knowledge, and demonstrate competency in the following areas: (1) awareness of self, (2) community engagement/public citizenship, (3) disciplinary knowledge, (4) strategic problem solving, (5) effective communication skills and (6) interpersonal collaboration/multiculturalism. Since the program is targeted towards fundamentally transforming the education of doctoral students in STEM and STEM-related disciplines, the inclusion of diverse students from across campus to form multidisciplinary teams is a critical component of this program [14]. This paper presents a description of the training model and preliminary findings following completion of the first year of the first cohort of doctoral students participating in the pilot program.

\section{Training Model}

Training in professional or "soft" skills, although not new in graduate education, is commonly done on an ad hoc basis, as a 'bolt on' to a student's program of study. Further, professional skills training is often targeted towards career placement and generally offered to students who are advanced in their graduate studies. While there has no doubt been some success in following this implicit approach, we sought to explore how a more explicit approach might better serve STEM graduate students.

The innovative model (see Figure 2) piloted through the GS LEAD program challenges that paradigm by positioning critical professional skills development [15], [13], [5] at the forefront of doctoral training and incorporating both personal and group reflection into experiential opportunities. Important elements of this model are the continued learning and mentoring opportunities available to the participants throughout their doctoral program following the initial training modules. Based on this model, training begins with facilitated instruction in professional skills, progresses to less-guided experiential learning, and incorporates faculty-to-student and peer-to-peer mentoring opportunities. The model infuses doctoral training with experiential learning and participants are encouraged to make community engagement/impact a compelling component of their dissertation research. In addition, the training model combines challengebased learning [16] with competency-based learning [17].

A recent paper by Feldon et al. [18] examined the impact of short-format programs such as traditional bootcamps and summer bridge programs on the development of graduate student research skills and the adoption of disciplinary specific attitudes/behaviors. They concluded that after analyzing data from 294 doctoral students at 53 institutions these traditional short-format interventions had no beneficial impact on student success or retention. The training model piloted here is very different from traditional bootcamps which tend to occur without follow up, are shortlived, and focus primarily on research skills. The pilot model described in this paper includes a highly immersive summer program that lasts a full semester and is followed by a second semester- 
long component in the fall. In addition, the model includes continued opportunities for students to incorporate their skills into their programs of study and dissertation research. By moving away from the 'sole' bootcamp-style program, spacing the learning opportunities over time [19]-[20] and integrating learning opportunities into their programs of study we hope to achieve more effective outcomes.

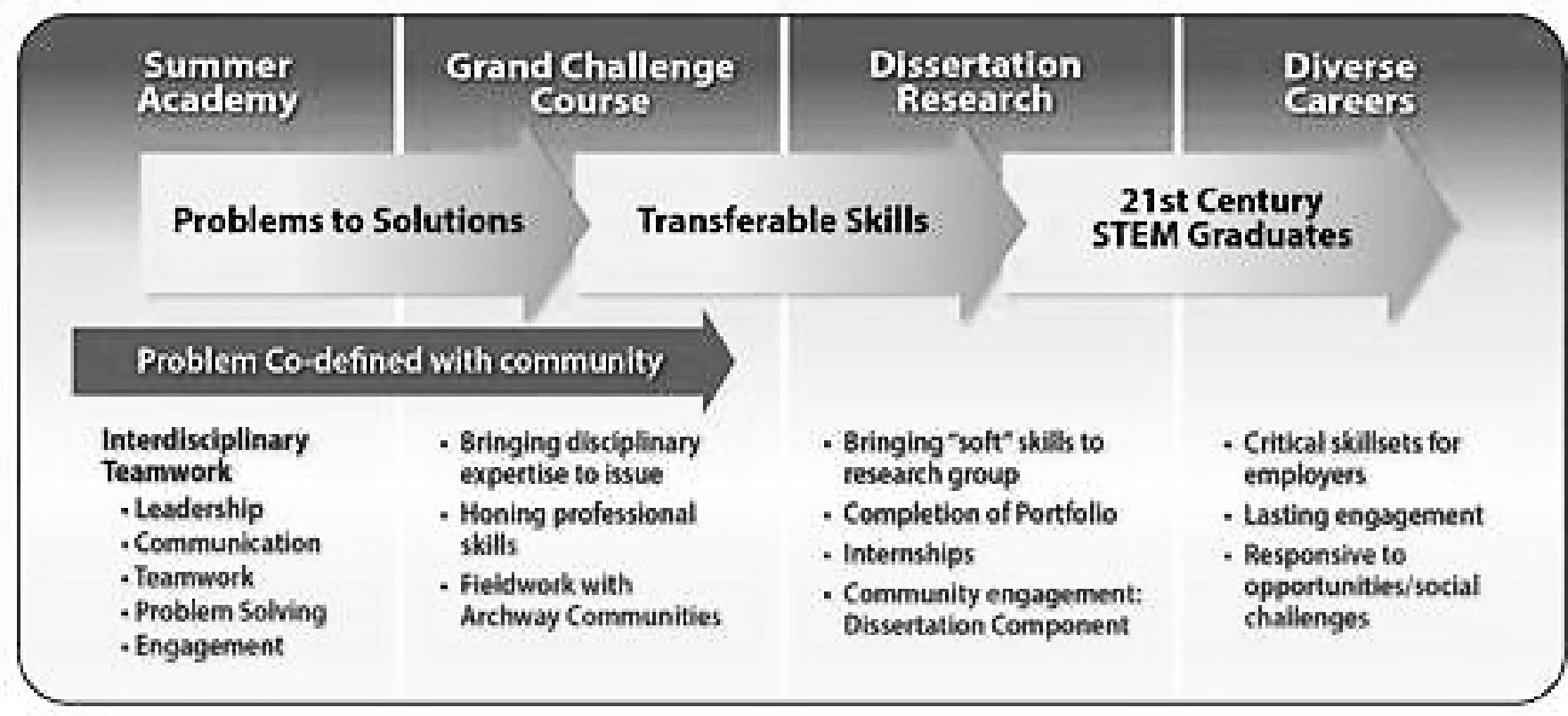

FIGURE 2. GS LEAD Training Model

Implementation of the training model began in summer 2016 with the first cohort of GS LEAD participants entering the GS LEAD Summer Academy. The Summer Academy was an immersive eight-week program designed for students to build foundational knowledge, hone transferable skills, and develop competency in key areas. In the course of a typical week students were engaged in program activities for two to three full days with additional take home assignments. The program was student-centered and included a mix of faculty-facilitated and student-led discussions/exercises, workshops, personal reflections, expert panels, and field trips [7], [21]-[23]. Table 1 details the various training modules provided during the academy.

An interdisciplinary team of faculty and staff from the UGA Fanning Institute for Leadership Development, and the UGA Colleges of Education, Engineering, Journalism \& Mass Communication and Veterinary Medicine facilitated the summer academy. During the academy the students also began to build relationships with potential community partners. Following completion of the summer program, the students advanced to a graduate level Grand Challenges course for the Fall 2016 semester. The challenge course was designed for students to internalize the processes and practices learned in the summer academy by putting these skills into action [24][26]. 
TABLE 1. Key Competencies

\begin{tabular}{l|l}
\hline $\begin{array}{l}\text { LEADERSHIP and } \\
\text { SELF-DISCOVERY }\end{array}$ & $\begin{array}{l}\text { Understanding Leadership, Understanding Self, } \\
\text { Leadership Styles, Learning and Personality Styles, } \\
\text { Leading Change, Risk Propensity }\end{array}$ \\
$\begin{array}{l}\text { INTERDISCIPLINARY } \\
\text { TEAMWORK }\end{array}$ & $\begin{array}{l}\text { Team Building, Collaborative Leadership, Group Decision Making } \\
\text { Cultural Competencies: Diversity, Multiculturalism, Inclusivity } \\
\text { Conflict Transformation }\end{array}$ \\
COMMUNICATION & $\begin{array}{l}\text { Communicating Effectively, Communication Styles, } \\
\text { Strategic Communication } \\
\text { Science Communication, Science and Storytelling, Understanding } \\
\text { Media }\end{array}$ \\
PROBLEM SOLVING & $\begin{array}{l}\text { Introduction to Problem-Project Concept, Design Thinking, } \\
\text { Community Engagement, Project Definition, } \\
\text { Problem Identification and Research, Integrating Communication } \\
\text { and Interdisciplinary Thinking into Projects }\end{array}$ \\
ENGAGEMENT & andTY
\end{tabular}

In the challenge course, students worked in teams with community partners to (1) understand the challenges faced by communities in solving local issues, (2) learn best practices in community engagement, and (3) develop a community project to be completed by the end of the semester [11]. The challenge course also provided training in the use of the design thinking concept for project development. During a typical week, the students would meet in a class setting for two hours to participate in design thinking training and to work on team projects. The students were then expected to spend additional time outside of class doing field work on their projects with their community partners. At the completion of the semester, the student teams were required to deliver final products that represented the culmination of their community projects. The final products were presented to a group of university and community stakeholders, and the presentations included strategies for product implementation.

\section{Student Participants}

The pilot program has the capacity for up to 15 participants per year. Potential participants were selected through an application process. Incoming doctoral students were nominated by their departments and applications were submitted to the Graduate School. In addition to standard academic metrics, applicants were asked to include a CV/resumé, and a personal statement of interest. For the first cohort year 2016, 12 students entered the program. Although the participants were largely from STEM/STEM-related disciplines, participation of students from outside of STEM was both welcomed and encouraged. The student participants comprised a diverse, multidisciplinary group from Arts and Sciences, Engineering, Education, Ecology, Public Health, and Public and International Affairs; as well as the Interdisciplinary Toxicology Program and the Integrative Conservation Program. 


\section{Evaluation Strategy}

The overall evaluation plan for assessing student learning and progress towards attaining the desired competencies was adapted from the Kirkpatrick four level evaluation model of Reaction, Learning, Behavior, and Results [27]. Table 2 (see below) outlines from the bottom up the planned objectives that we have for students at each of the four levels.

TABLE 2. Levels of Evaluation for GS LEAD Training Program

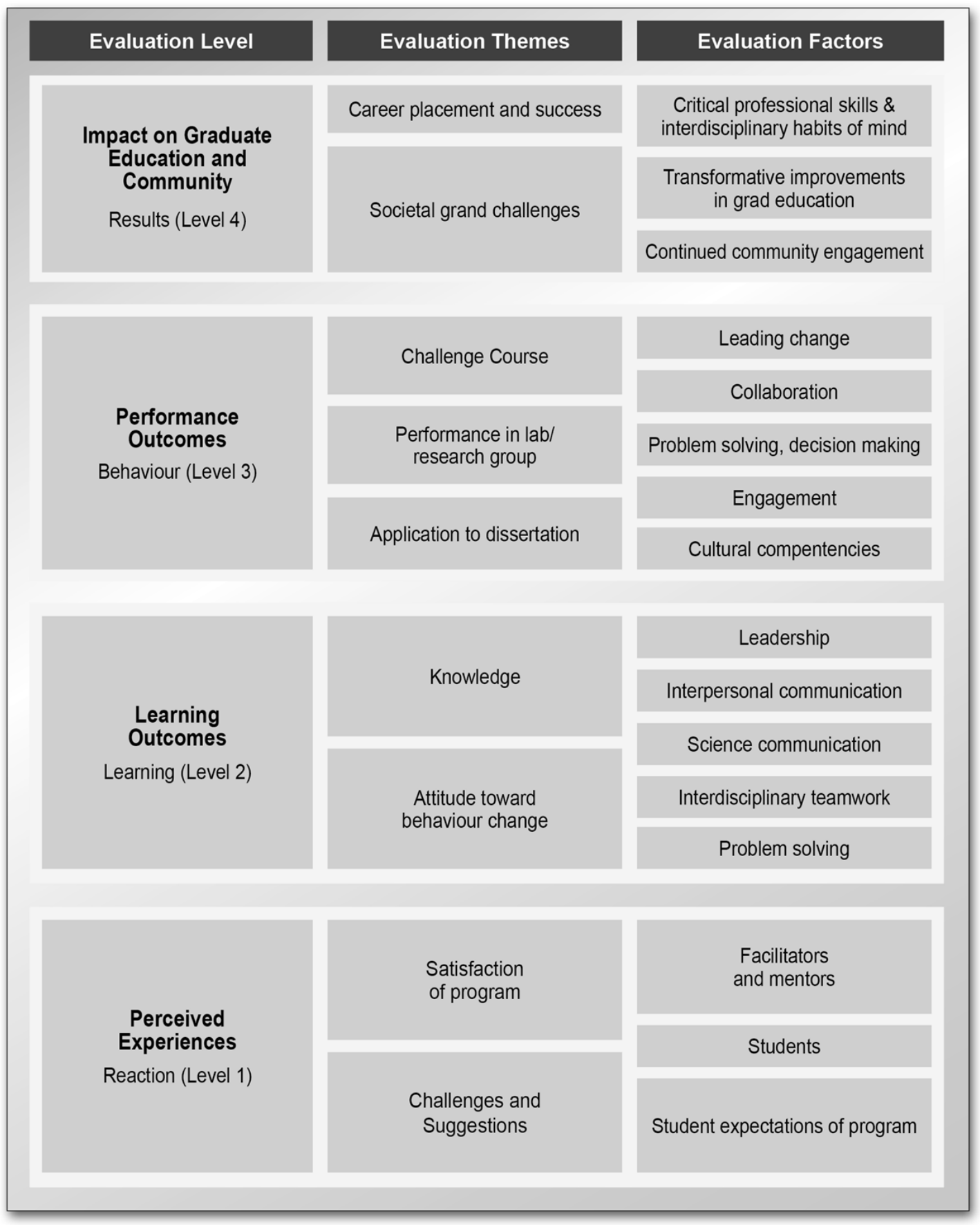


The evaluation approach includes the collection of data from doctoral students, faculty instructors, community stakeholders and faculty mentors. A number of modalities are employed to collect data for assessment and include the use of survey instruments, style and awareness inventories, observation of class dynamics, role-playing exercises, interviews, reflection posts, project deliverables, scholarly works, portfolios and dissertation products.

The first level of evaluation, Reaction, is designed to measure how participants perceived their experiences (react) to the program. It focuses on whether participants were pleased with the program and whether they found it relevant to their research. Positive reactions make learning (level two) more likely. The Learning level (level two) seeks to determine whether students effectively acquired the material. Level three, Behavior, focuses on measurable changes in student behavior and whether the acquired skills were utilized. Level four seeks to understand the broad Results of the training program and the impact that it has at the university and in the community.

\section{Results and Discussion}

It is important to emphasize that this pilot program is ongoing thus the results are preliminary. There is a wealth of data still to be analyzed from the first cohort and two more cohorts are in progress or planned. Given the novel design of the program it is worth reporting our findings to date. Based on preliminary evaluation of this first cohort, student participants perceived their experiences positively (Level 1 Reaction). For instance, using a 5-point Likert scale ranging from 1 (strongly disagree) to 5 (strongly agree) students were asked to respond to the question 'the session had a positive impact on my development as a STEM Scholar Leader' for each of the different learning activities in which they participated during the Summer Academy. The mean score was $4.02(\mathrm{SD} \pm 0.51)$.

In addition, preliminary results from interviews in which students shared their personal transformations and realizations based on their experiences in the program revealed the following emerging themes: (1) interdisciplinary mindsets (2) community engagement (3) understanding self as leader (4) professional identity and (5) STEM scholar leadership. The emergence of these themes is in alignment with our identified competencies and suggests learning in these areas. Further, the reflective discussions posted by the students following expert panel discussions and field trips revealed that these 'real world' applications positively impacted the student experience and contributed to growth in the six competencies areas. Additionally, at least two of the team project deliverables developed during the Grand Challenges course are already being incorporated and implemented by their community partners.

Our preliminary findings also identified a few areas in need of improvement. For example, the length of the summer academy was perceived as too long and negatively impacted student learning. Interestingly, while the expert panels and field trips were positive factors in student learning, the number of expert panels and field trips were perceived as negatively impacting learning. Notably, there was a clear perception of disconnect between the summer academy and the subsequent challenge course. This disconnect was determined to be due, in large part, to an inadequate level of transition between the two very distinct learning environments. In addition, our preliminary assessment suggests that specific scenarios/themes for community collaboration as well as challenge projects should be explored to enhance student experiences and learning. These identified areas of needed improvement are critical and have informed program revisions in both the summer academy and challenge course for future cohorts. These revisions include shortening 
of the summer academy, introducing the design thinking concept earlier in the summer program, and moving the development of the community project into the fall challenge course. Further evaluation is currently underway to determine the impact of these changes on student learning.

\section{Summary and Concluding Remarks}

The training model presented in this paper is unique in its focus to bridge STEM education, with interdisciplinary attitudes and community engagement. The recent review by Morin et al. [12] highlights the progress of community engagement in graduate education over the past 10 years and discusses the positive impact that interdisciplinary perspectives bring to the process. In particular these authors note the critical need to "continually seek innovative ways to embed community engagement within disciplines that face the greatest barriers to participation". It is our hope that this pilot program will provide an effective framework to equip STEM graduate students with the skills necessary to be productive, engaged scholars, and encourage graduate educators to engage students from across disciplines to work together on complex issues of importance to the public.

\section{Acknowledgements}

This material is based upon work supported by the National Science Foundation under Grant No. 1545341. We would like to thank students that participated in the study.

\section{References}

[1] Organization for Economic Cooperation and Development (OECD), Transferable Skills Training For Researchers: Supporting Career Development And Research. OECD Publishing, 2012.

[2] National Research Council, Research Universities And The Future Of America: Ten Breakthrough Actions Vital To Our Nation's Prosperity And Security. Washington, D.C.: The National Academies Press, 2012.

[3] National Institutes of Health (NIH), Biomedical Research Workforce Working Group Report. http://acd.od.nih.gov/biomedical_research_wgreport.pdf., 2012.

[4] President's Council of Advisors on Science and Technology (PCAST. ) “Transformation and opportunity: The future of the U.S. research enterprise”, Report to the President, 2012.

[5] C. Wendler, B. Bridgeman, R. Markle, F. Cline, N. Bell, P. McAllister and J. Kent. Pathways Through Graduate School And Into Careers. Princeton, NJ: Educational Testing Service, 2012.

[6] H. S. Barrows, Practice-Based Learning: Problem-Based Learning Applied To Medical Education. Springfield, IL: Southern Illinois University, 1994.

[7] H. S. Barrows, How To Design A Problem-Based Curriculum For The Preclinical Years. New York, NY: Springer, 1985.

[8] I. Choi, Y. C. Hong, H. Park, and Y. Lee, “Case-based learning for anesthesiology: Enhancing dynamic decision-making skills through cognitive apprenticeship and cognitive flexibility,” in Handbook On Design In Educational Technology, R. Luckin, P. Goodyear, B. Grabowski, S. Puntambeker J. Underwood, and N. Winters, Eds. New York: Routledge, 2013, pp. 230-240.

[9] A. J. Neville, "Problem-based learning and medical education forty years on”, Medical Principles and Practice, vol 18, pp. 1-9, 2009.

[10] V. T. Patel, G. J. Groen, and G. R. Norman, "Effects of conventional and problem-based medical curricula on problem solving”, Academic Medicine, vol 66, pp. 380-389, 1991.

[11] H. E. Fitzgerald, K. Bruns, S. T. Sonka, A. Furco, and L. Swanson, “The centrality of engagement in higher education”, Journal of Higher Education Outreach \& Engagement, vol 16, pp. 7-27, 2012.

[12] S. M. Morin, A. J. Jaeger and K. O’Meara, “The state of community engagement in graduate education: reflecting on 10 years progress”, J. Higher Education Outreach and Engagement, vol 20, pp. 151-156, 2016. 
[13] D. M. Richter and M.C. Paretti, M.C. "Identifying barriers to and outcomes of interdisciplinarity in the engineering classroom”, European Journal of Engineering Education, vol 34, pp. 29-45, 2009.

[14] C. E. Hmelo-Silver, “Problem-based learning: What and how do students learn?”, Educational Psychology Review, vol 16, pp. 235-266, 2004.

[15] J.W. Pellegrino and M. L. Hilton, "Education for life and work". Committee On Defining Deeper Learning And $21^{\text {st }}$ Century Skills, National Research Council, 2012.

[16] K, Magnusson and J. Osborne, "The rise of competency-based education: A deconstructionist analysis", J. Educ. Thought, vol 24, pp. 5-13, 1990.

[17] S. Hodge, "The origins of competency-based training", Aust. J. Adult Learn, vol 47, pp. 179-209, 2007.

[18] D. F. Feldon, S. Jeong, J. Peugh, J. Roksa, C. Maahs-Fladung, A. Shenoy and M. Oliva. "Null effects of bootcamps and short-format training for PhD students in life sciences," Proc. Natl. Acad. Sci., vol. 114, pp. 9854-9858, April 2017.

[19] S. K. Carpenter, N. J. Cepeda, D. Rohrer, S. H. Kang, and H. Pashler, "Using spacing to enhance diverse forms of learning: Review of recent research and implications for instruction”, Educ. Psychol. Rev. vol 24, pp. 369-378, 2012.

[20] D. Rohrer, "Student instruction should be distributed over long time periods", Educ. Psychol. Rev. vol 27, pp. 635-643, 2015.

[21] H. G. Schmidt, and M. de Volder, Tutorials In Problem-Based Learning: New Directions In Training For The Health Professions. Assen, The Netherlands: Van Gorcum, 1984.

[22] J. P. Dugan and S. R. Komives, "Developing leadership capacity in college students: Findings from a national study", in A Report from the Multi-Institutional Study of Leadership, College Park, MD: National Clearinghouse for Leadership Programs, 2007.

[23] U. B. Kjaerulff, C. A. F. Rosenstand, J. Stage, and M. Vetner, M. "Case-based learning (CBL) - A new pedagogical approach to multidisciplinary studies”, in $36^{\text {th }}$ SEFI Annual Conference 2008 - Quality Assessment, Employability and Innovation, F. Fink, Ed. Sense Publishers, 2008.

[24] N. Baloian, K. Hoeksema, U. Hoppe, U. and M. Milrad, "Technologies and educational activities for supporting and implementing challenge-based learning," in Education for the $21^{\text {st }}$ Century - Impact of ICT and Digital Resources, D. Kumar and J. Turner, Eds. Boston: Springer, 2006, pp. 7-16.

[25] L. Johnson, and S. Brown, Challenge Based Learning: The Report From The Implementation Project. Austin, Texas: The New Media Consortium, 2011.

[26] L. F. Johnson, R. S. Smith, J. T. Smythe, and R. K. Varon, Challenge-Based Learning: An Approach For Our Time. Austin, Texas: The New Media Consortium, 2009.

[27] D. L. Kirkpatrick, and J.D. Kirkpatrick. Evaluating Training Programs: The Four Levels ( $3^{\text {rd }}$ Edition). San Francisco: Berrett-Koehler Publishers, Inc., 2006 